\title{
Study on Deterioration of Machining Performance by EDMed Sludge and its Prevention
}

\author{
Akihiro GJTO*, Takashi YUZAWA*, Takuji MAGARA* and Kazuhiko KOBAYASHI*
}

(Received on March 17, 1997)

* Nagoya Works, Mitsubishi Electric Corp., Nagoya 461, Japan

Abstract

This paper describes a phenomenon caused by EDMed sludge. When the electrode comes in touch with the workpiece through EDMed sludge, current flows through the sludge and the bridge of sludge is made. When this bridge is made, it brings about the concentration of discharge pulses and damages the machined surface.

In order to improve the machining performance, the method to prevent formation of the bridge of sludge is discussed. It becomes clear that when the electrode and the workpiece are short-circuited, interruption of current is effective to improve machining performance.

Key words : EDM, sludge, short, machining speed

\section{INTRODUCTION}

In EDMing, When the electrode and the workpiece come in touch, current flows without discharging. But the influence of the current that flows when the electrode and the workpiece touch had not been considered and is kept unknown. This is because it is thought that the current in electrical contact has no effect to the machining performance, for EDM is machining process with the discharge pulse current. Besides the relation between the current in electrical contact and the machining performance has not been clear.

However, according to the recent machining examples, we have come to know that when the electrode and the workpiece come in electrical contact the following problems are caused,

(1) Once the short occurs, it tends to continue long time, and machining speed becomes slow.

(2)When the short occurs, the electrode and the workpiece tend to be damaged.

Those phenomena seem to have close relation to the EDMed sludge. The behavior of sludge in EDM are studied by many researchers ${ }^{1,-4)}$, but the behavior when the short occurs is not studied. This paper aims to make clear the cause of those problems and improve the finishing machining performance of EDM.

\section{INFLUENCE OF SHORT CURRENT}

\subsection{Gap condition in short}

When short occurs in EDM, it tends to continue long time such as several $100 \mathrm{~ms}$ from several $10 \mathrm{~ms}$. Figure 1 shows the gap voltage waveform in EDM. The electrode is copper $10 \mathrm{~mm}$ square, and the workpiece is steel. The electrode conditions are as follows;

Ip:5.5A,

ON-time: $64 \mu \mathrm{s}$,

OFF-time: $16 \mu \mathrm{s}$.

The figure shows that short continues about $100 \mathrm{~ms}$.

When short occurs in EDM, the gap distance widens by servo as that short dissolves. For example, gap distance grow some $10 \mu \mathrm{m}$ wider in $100 \mathrm{~ms}$. If short is just mechanical contact between the electrode and the workpiece, it seems to be dissolved easily when gap distance becomes several $\mu \mathrm{m}$ wider.

Figure 2 shows the sludge when gap shorts. Short current flows through the sludge in the gap. This figure is the look from the top. Magnetic field is generated by the effect of the short current. The value of the magnetic field $\mathrm{B}$ is shown as following equation.

$$
\mathrm{B}=\mu \mathrm{I} /(2 \pi \mathrm{a})
$$
(a:radius of the circle through which short current

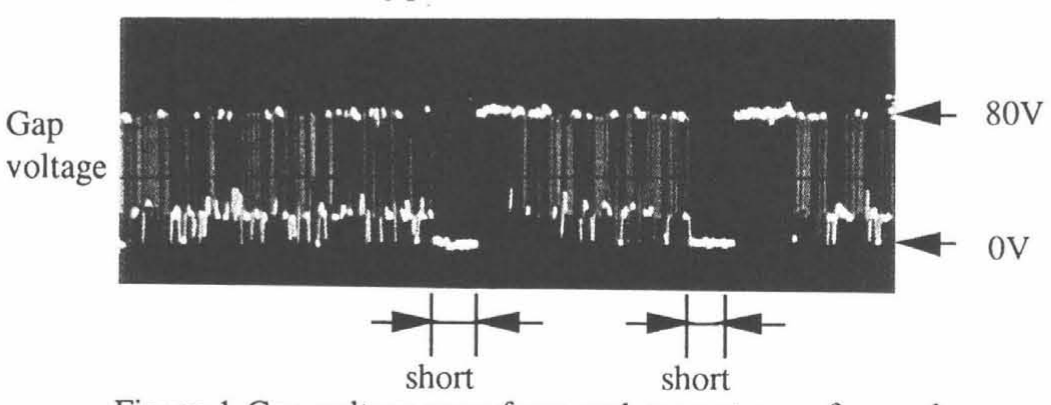

Figure 1 Gap voltage waveform and current waveform when gap is short-circuited. current, $\mu$ :permeability of dielectric fluid)

It is assumed that the gap distance is much longer than $a$.

2.2 Force that affects the sludge By the magnetic field $\mathrm{B}$, the sludge that is around the area in which short current flows is affected the force to the center of the area. Each particle of sludge accept the force $\mathrm{F}$ from the mag-
flows,I:short 


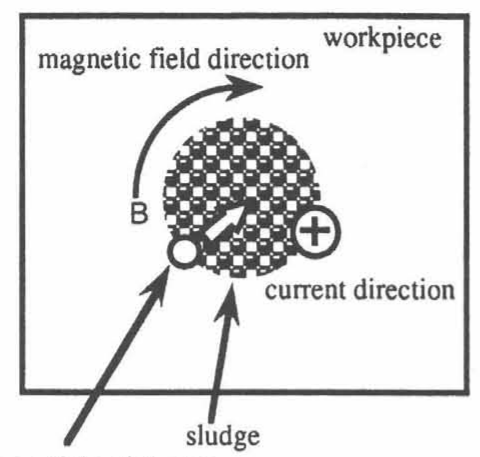

any particle of sludge

Figure 2 Force that a particle of sludge receives

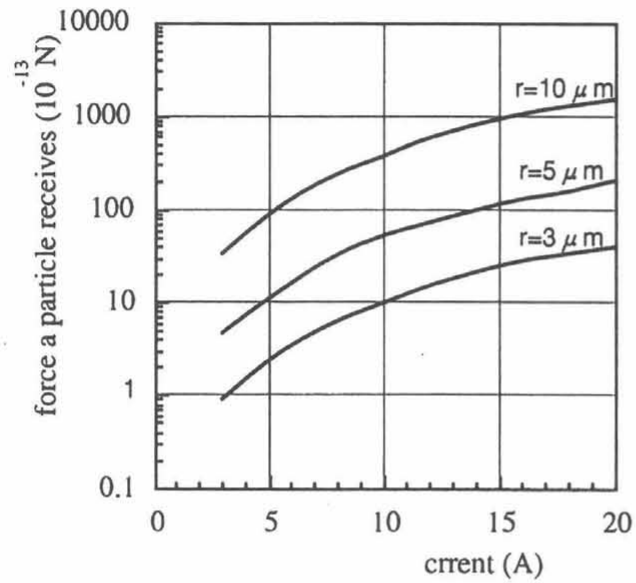

Figure 3 Force each particle receives

which short current flows is affected the force to the center of the area. Each particle of sludge accept the force $\mathrm{F}$ from the magnetic field;

$$
\mathrm{F}=\mathrm{B} \cdot \mathrm{i} \cdot 2 \mathrm{r}
$$

(i:curent that flows through a particle of sludge,r:radius of each particle of sludge)

$\mathrm{F}$ is expressed as follows when the equation (2.1)is inserted into the equation (2.2).

$$
\begin{aligned}
\mathrm{F} & =\mathrm{B} \cdot \mathrm{i} \cdot 2 \mathrm{r} \\
& =\pi \frac{\mathrm{I}}{2 \pi \frac{\mathrm{I}}{2 \pi \mathrm{r}^{2}}} \mathrm{a}^{2} 2 \mathrm{r} \\
& =\pi \frac{\mathrm{I}^{2} \cdot \mathrm{r}^{3}}{\pi \mathrm{a}^{3}}
\end{aligned}
$$

Figure 3 shows the the relation between the average machining current and the force a particle of sludge accepts when $\mathrm{a}=1 \mathrm{~mm}$.

The acceleration a particle of sludge accepts is shown as the next equation;

$$
\begin{aligned}
\alpha & =\frac{\mathrm{F}}{\mathrm{m}}=\frac{\mathrm{F}}{\frac{4}{3} \pi \mathrm{r}^{3} \rho} \\
& =\frac{3 \mu \mathrm{I}^{2}}{4 \pi^{2} \rho \mathrm{a}^{3}}
\end{aligned}
$$
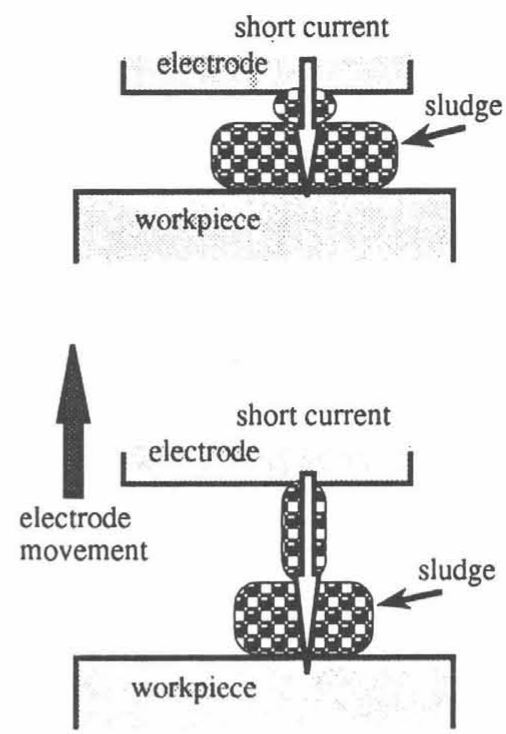

Figure 4 Appearance when gap shorts

(m:mass of a particle of sludge, $\rho$ :dencity of sludge(steel))

For example, when $\mathrm{I}=5 \mathrm{~A}, \mathrm{a}=1 \mathrm{~mm}$ and $\mathrm{r}=5 \mu \mathrm{m}$ are inserted to (2.3),(2.4), F and $\alpha$ are calculated as follows;

$\mathrm{F}=1.25 \times 10^{-12}(\mathrm{~N}), \alpha=0.3\left(\mathrm{~m} / \mathrm{s}^{2}\right)$

This result shows that the sludge accept force that is strong enough to gather when short current flows.

As a result, when short current flows, even if the gap between the electrode and the workpiece become wider, it is difficult to dissolve short. Figure 4 shows such a situation.

This assumption is ascertained by the following experiment. First, the electrode ahd the workpiece are shorted through the sludge. Then, the gap between the electrode and the workpiece are widen until it becomes more than $1 \mathrm{~mm}$, keeping the short current flowing. Figure 5 shows the bridge of sludge from the workpiece to the electrode at this experiment. From now on we call it "short bridge". We certainly confirm the existance of short bridge in this figure. However, when the currentis turned off at this moment, short is disolved and gap becomes open.

As stated above, it is ascertained that when the short current flows the sludge is gathered and forms a short bridge and that even if the gap becomes wider it is difficult to break the bridge. And it is also ascertained that current is turned off when the gap shorts the growth of the short bridge can be prevented.

\subsection{Effect to the surface quality}

The effect of the short bridge to the machined surface quality is considered. When the gap is short, the gap becomes wider. So usualy the short bridge is 


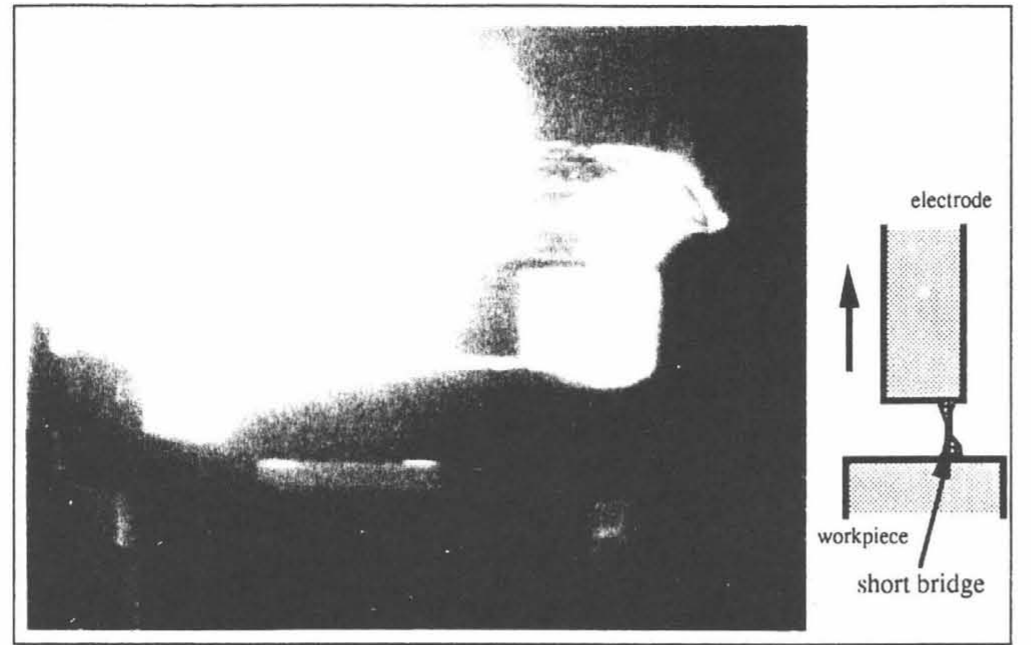

Figure 5 Short bridge

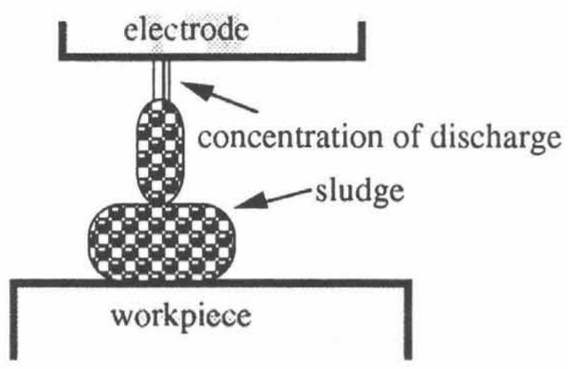

Figure 6 Concentration of discharge

broken when the gap distance becomes limit to maintain the bridge. However, even when the short bridge is broken, the sludge is dense around the bridge area, and it is likely to discharge at this area (Figure 6).

The concentration of discharge around the broken bridge is thought to do the damage to the machined surface.

\subsection{Relation between peak current and frequency of short pulse}

Figure 7 shows the relation between the peak current and the frequency of short pulse. $10 \mathrm{~mm}$ square copper is used as an electrode, and the ratio of the number of short pulses in all pulses are measured every $2 \mathrm{~mm}$ depth. 3 kinds of peak current is used(3.5A, $5.5 \mathrm{~A}, 10 \mathrm{~A})$, on-time is $64 \mu \mathrm{s}$, off-time is $16 \mu \mathrm{s}$. It shows that the frequency of short pulse is high when Ip is small. The force to gather sludge is bigger when Ip is large. Short pulse is more frequent as Ip is smaller. Though the force to gather sludge is larger when the Ip is larger, frequency of short pulse is high when the Ip is small. It is thought to be the following two reasons. First, when the peak current
(Ip) is larger the clearane between the electrode and workpiece is wider and sludge is easy to be flown away. Second, a short bridge is

broken by the heat of discharge more easily when Ip is large.

\section{SHORT CURRENT PREVEN- TION CIRCUIT}

\subsection{Principle of gap short detection}

As stated above, when short current flows, short continues long time and it causes flaws of the electrode or the workpiece. For this reason it is necessary to stop short current in order to prevent the sludge from concentrating and making a bridge.

It is considered how to check short condition and to stop short current. We call this circuit "Short Current Prevention Circuit". Figure 8 shows the principle of Short Current Prevention Circuit. As figure shows, During off-time it is checked whether gap is short or not, and when it is short, next pulse is eliminated.

3.2 Effect of the Short Current Prevention Circuit The expriment in order to investigate the effect of the Short Current Prevention Circuit is done.

\subsubsection{Cling object to graphate electrode}

\section{(1) details of experiment}

The Short Current Prevention Circuit is designed for the purpose of solve the problem caused by the short between the electrode and the workpiece through the sludge in the gap. For this reason, it has advantage in the cases that the electrode shape is complicated in which sludge is difficult to be flown out of the gap. Figure 9 shows an example, which has tapered side surface. With such an electrode, it is difficult to put sludge out of the gap even when the jump movement of the electrode is done. Machining conditions in this experiment is as follows; workpiece SKD11(steel) electrode taper shaped graphite e l e c t r i c a 1 cronditions : multi-step conditions

flushing conditions : no flushing

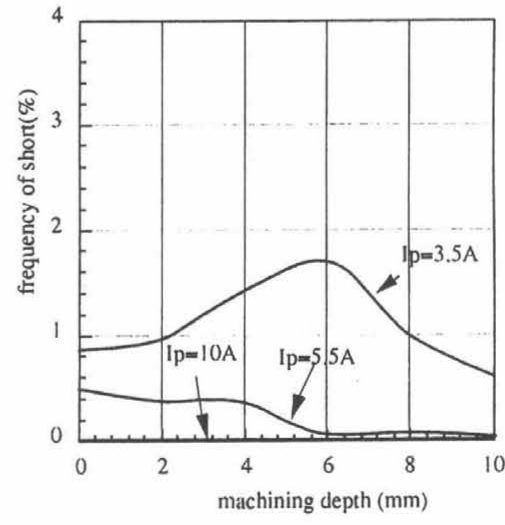

Figure 7 Frequency of short 


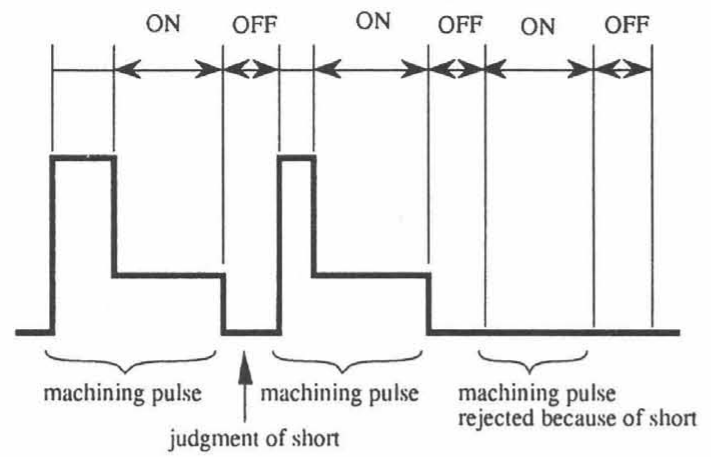

Figure 8 Method to detect gap short

(2)result

Sometiong like carbon which seems to be decomposition of dielectric fluid adheres to the surface of the electrode (figure 9). And it is copied to the workpiece and pits are made on the surface. This is scab-like object, and easy to come off when it is scratched. This adheseion can not be reduced by changing off-time conditions or jump movement conditions of the electrode. While machining with the electrode, short pulses is frequently occured. In this case adhiseion can be eliminated with the Short Current Prevention Circuit.

Figure 10 shows the comparison of workpiece surfaces between "with the Short Current Prevention Circuit" and "without the Short Current Prevention Circuit". Without the Short Current Prevention Circuit the surface has many pits on it. For those pits were made in rough machining, finishing machining was not done.

3.2.2 Flaw of electrode or workpiece

(1)details of experiment

Next, the effect to reduce flaws of electrode or the workpiece is examined. With the electrode shown in figure 11 , rough machining is done, and then finishing machining is done with a little larger sized electrode. The dielectric fluid is flushed into the gap between the side surface of the electrode and the workpiece. Because finishing ma-

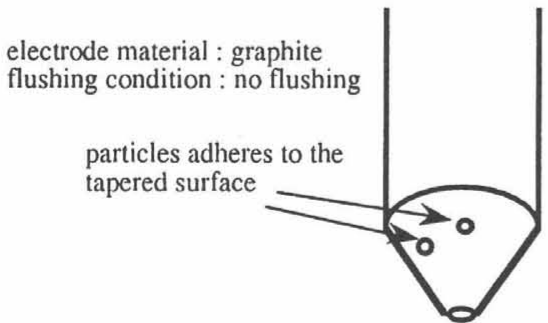

Figure 9 Tapered shaped graphite electrode chining electrode is a little larger than the rough machining electrode, discharge begins at side surface of the electrode in the finishing machining. Machinig conditions are shown below;

\section{(2)result}

In this case sludgeis stagnated at the another side surface of the electrode which is an outlet of flushed dielectric fluid. While machining, short pulses are frequently observed. The magnified surface pictures are shown in figure 13. Withoust the Short Current Prevention Circuit, there are many pits on the machined surface, while with the Short Current Prevention Circuit, there is no flaws on the surface. The effect of the Short Current Prevention Circuit is confirmed.

\section{BREAKIN OF THE SHORT BRIDGE - SHORT BRIDGE ELIMINATION CIRCUIT -}

In last paragraph the effect of the Short Current Prevention Circuit is discussed. In this paragraph, the method to increase machining speed of EDM with the Short Current Prevention Circuit is discussed. The method of the Short Current Prevention Circuit is passive way. It means that when gap short is detected, current is stopped, but it does nothing to dissolve short. consequently, it has almost no effect to improve machinig speed when short pulse frequently appears. In this respect the method is discussed to prevent progress of short bridge and simultaneously to increase machining speed.

\subsection{Principle of the short bridge elimination}

We have the opinion that in most cases short- 
circuit is caused not by i m mediage contact of the electrode and the workpiece, but by sludge between them. Therefore when short continues for a while and the gap distant becomes wider,

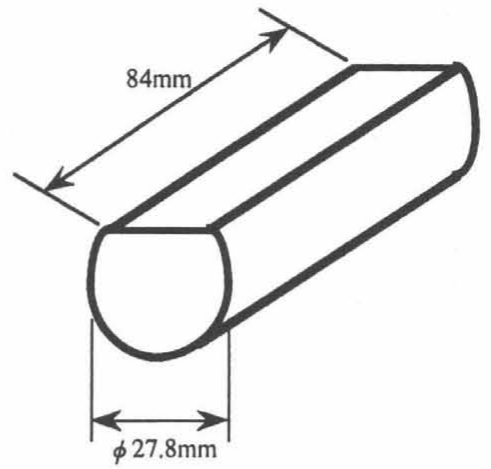

Figure 11 Cylindrical copper electrode the diameter of the short bridge shrinks as shown in figure 14.

We consider that short current effects twe influence when electrode and workpiece short;

(1) to make sludge particle gather and build a short bridge.

(2) to break a short bridge by the energy of short current.

when sludge particles gather and make a bridge, effect (1) is greater than (2). While current flows when bridge is thin, effect (2) can be bigger than (2) and the short bridge can be broken.

4.2 Structure of the Short Bridge Elimination Circuit

The Short Bridge Elimination Circuit has a function to generate current pulses to break short bridge in addition to the Short Current Prevention Circuit. After this, we call this circuit "the Short Current Control Cicuit" including both functions.

When short is detected, next pulse is elimi-

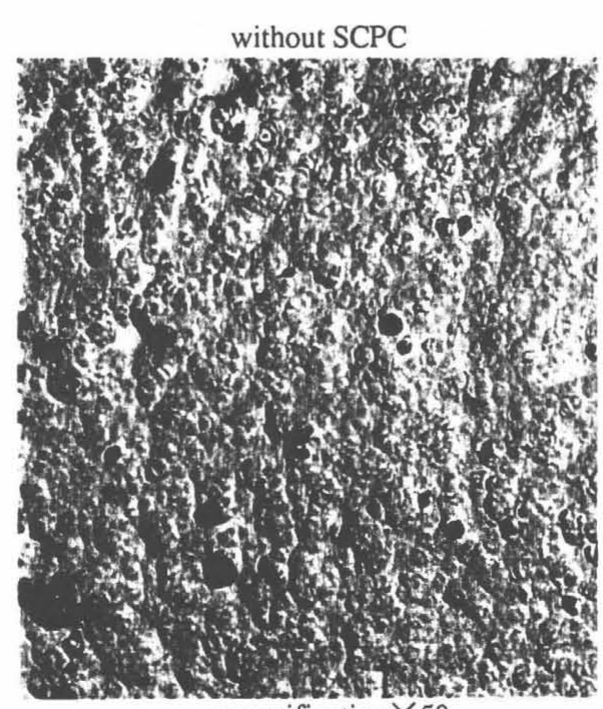

magnification $\times 50$

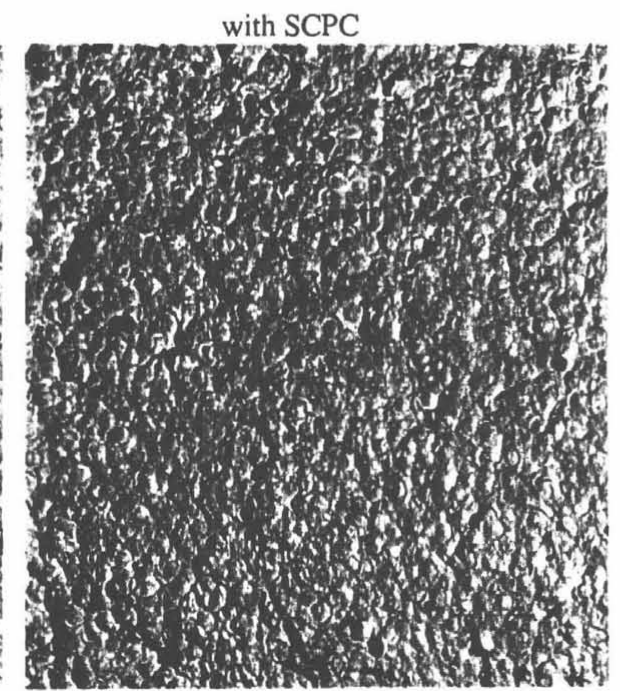

magnification $\times 50$
Figure 13 Comparison of machining surfaces

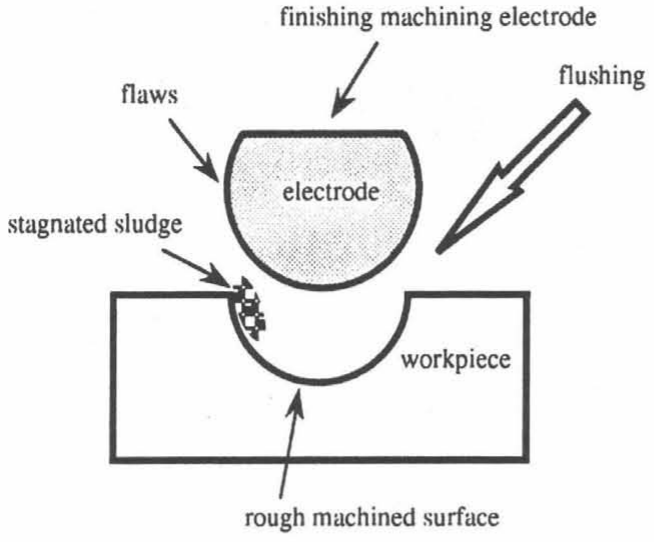

Figure 12 Machining example

nated and short duration is measured. When short duration becomes presetted value, a current pulse to break a bridge is launched (figure 15, figure 16). de Bruny reported that high-peaked-and-short-width current pulses enables stable machining, but to flow current when short is detected can make the short bridge grow. It is better to launch current pulse after long short duration because bridge becomes thin and easy to break.

4.3 Effect of the Short Bridge Elimination Circuit 4.3.1 Breaking short bridge

The effect of the Short Bridge Elimination Circuit to break short is discussed.

(1) conditons

The ratio of dissolving short after the short bridge breaking pulse is measured. It is measured every $2 \mathrm{~mm}$ depth. Machining conditions are as follows; workpiece:SK3(steel)

electrode:copper $(10 \mathrm{~mm}$ $\times 10 \mathrm{~mm}$ square)

(2) result

Figure 17 shows the ratio of dissolving short-circuit. It is confirmed that short-circuit is dissolved almost $100 \%$ by the Short Bridge Breaking Pulse. It is considered by this result that machining speed can be increased.

4.3.2 Finishing machining speed and electrode wear ratio

(1) details of experiment Finishing machining speed and the ratio of electrode-workpiece wear is compared between the circuit with the 


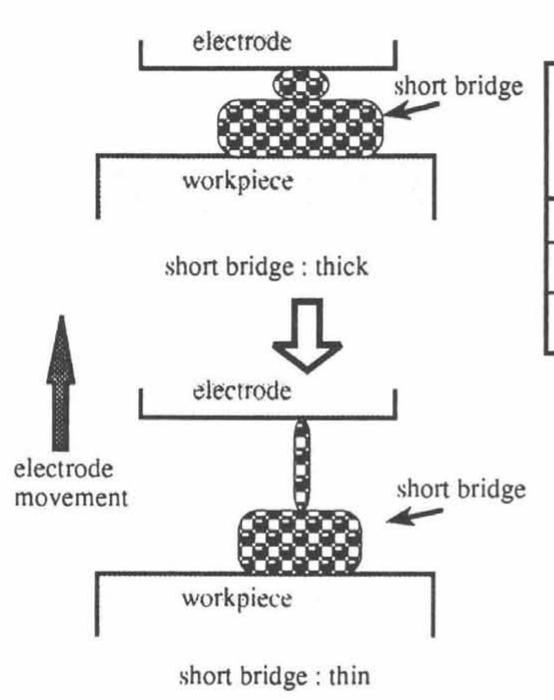

Figure 14 Short bridge

Short Current Control Circuit and without it. workpiece:SK3(steel) electrode:copper pipe(figure )

machinig time: 1 hour

(2) rasult

Table 1 shows the result of machining speed and the ratio of electrode-workpiece ratio. By the circuit with the Short Current Control Circuit, finishing machining speed is greatly improved, and electrode wear almost the same.

\section{CONCLUSIONS}

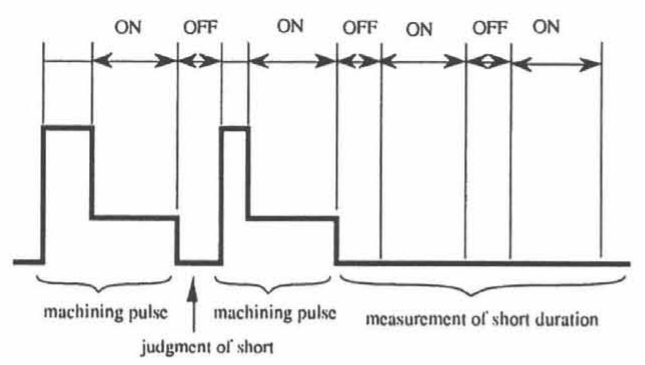

Figure 15 Measurement of short duration

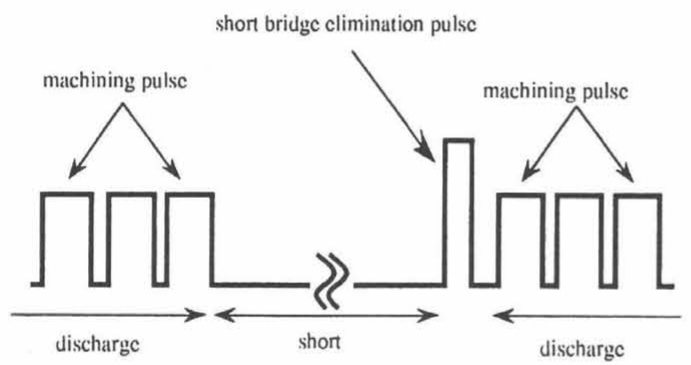

Figure 16 Short bridge elimination pulse
Table 2 Comparison of machining speed and electrode wear

\begin{tabular}{|l|c|c|c|c|}
\hline \multirow{2}{*}{ machining conditions } & \multicolumn{2}{|c|}{ without SCCC } & \multicolumn{2}{c|}{ with SCCC } \\
\cline { 2 - 5 } & $\begin{array}{c}\text { electrode wear } \\
(\%)\end{array}$ & $\begin{array}{c}\text { machining speed } \\
(\mathrm{mg} / \mathrm{min})\end{array}$ & $\begin{array}{c}\text { electrode wear } \\
(\%)\end{array}$ & $\begin{array}{c}\text { machining speed } \\
(\mathrm{mg} / \mathrm{min})\end{array}$ \\
\hline Ip3.5A,ON16 $\mu \mathrm{s}, \mathrm{OFF} 16 \mu \mathrm{s}$ & 4.0 & 10.7 & 4.3 & 17.1 \\
\hline Ip5.5A,ON32 $\mu \mathrm{s}$, OFF32 $\mu \mathrm{s}$ & 2.0 & 24.9 & 2.4 & 38.2 \\
\hline Ip15A,ON256 $\mu \mathrm{s}$, OFF256 $\mu \mathrm{s}$ & 0.30 & 175 & 0.38 & 234 \\
\hline
\end{tabular}

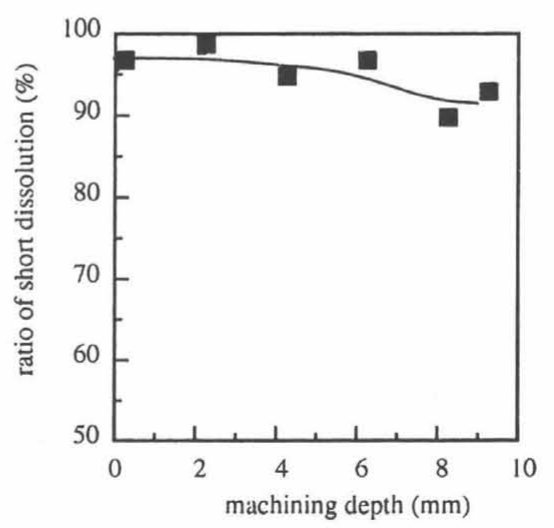

Figure 17 Ratio of short dissolution ( $\mathrm{Ip}=15 \mathrm{~A})$

The effect of short current is discussed, and the conclusions are as follows;

(1) Particles of sludge is gatherd by short current and make a short bridge. It causes long duration of short, decrease machining speed, or causes flaws of the electrode or the workpiece.

(2) It is confirmed that the Short Current Prevention Circuit can prevent the damage to the workpiece or the electrode which is caused by the stagnation of sludge.

(3) It is confirmed that the Short Bridge Elimination Pulse dissolve short.

(4) Frequency of short pulses can be reduced by the Short Bridge Elimination Pulse.

(5) The Short Current Control Circuit can increase the finishing machining speed.

\section{REFERENCES}

1) Suda, Sata : Behavior of particles in the gap of EDM, Journal of the Japan society of electrical-machining engineers, Vol.7, No.14, 19-28, 1974

2) Motoki, Ono, Kamiide : Phenomina in EDM gap, Journal of the Japan society of electrical-machining engineers, Vol.8, No.15, 44-53, 1974

3) Kunieda, Yanatori : Study on debris movement in EDM gap, International Journal of Electrical Machining, No.2, 1997

4) H.E.de Bruyn : A stable process with trapezoidal pulses, Proceeding of the 7th International Symposium for Electromachining, 77-86, 1983 